Revista Educação e Políticas em Debate - v. 9, n. 2, p. 489 - 508, mai./ago. 2020 - ISSN 2238-8346

\title{
Gestão Universitária: a relação entre as características do Corpo Docente e o Desempenho Discente ${ }^{1}$
}

\author{
University Management: the relationship between the Academic Staff characteristics and the Students \\ Performance
}

\author{
Gestion Universitair e la relation entre les caractéristiques du Personnel Académique et la \\ Performance des Étudiants
}

\author{
Alyne Alves Trindade 2 \\ Universidade Estácio de Sá \\ Jose Geraldo Pereira Barbosa ${ }^{3}$ \\ Universidade Estácio de Sá \\ Marco Aurélio Carino Bouzada ${ }^{4}$ \\ Universidade Estácio de Sá
}

Resumo: Esta pesquisa procurou explicar, por meio de regressões múltiplas, a relação entre 7 fatores característicos dos docentes e o desempenho dos discentes medido a partir do Exame Nacional de Desempenho de Estudantes (ENADE) e Indicador da Diferença entre os Desempenhos Observado e Esperado (IDD). A pesquisa com abordagem quantitativa coletou dados de 63 cursos/campi nas bases de dados do Instituto Nacional de Estudos e Pesquisas (INEP) e da Universidade Estácio de Sá (UNESA). Os resultados da pesquisa indicam a relevância de iniciativas de: (i) valorização dos professores com titulação de doutor, (ii) melhoria do processo de orientação de trabalhos de conclusão, (iii) gerenciamento da experiência no magistério (idade) e (iv) análise e reflexão sobre os resultados da avaliação da prática pedagógica, com a finalidade de melhorar o desempenho dos discentes.

Palavras chave: Gestão Universitária. Características do Docente. ENADE. Desempenho.

Abstract: This research sought to explain, through multiple regressions, the relationship between 7 characteristic factors of teachers and student performance measured from the National Student Performance Exam (ENADE) and Indicator of the Difference between Observed and Expected Performance (IDD). The research with a quantitative approach collected data from 63 courses / campuses in the databases of the National Institute of Studies and Research (INEP) and the University Estácio de Sá (UNESA). The results of the research indicate the relevance of initiatives such as: (i) valorization of professors with a doctorate, (ii) improvement of the orientation process for completion work, (iii) management of teaching

\footnotetext{
1 Uma versão preliminar deste trabalho foi apresentada no $3^{\circ}$ Simpósio Avaliação do Ensino Superior (AVALIES 2017). A presente versão inclui material adicional assim como incorpora melhorias decorrentes de contribuições dos avaliadores do Simpósio.

2 Mestre em Administração e Desenvolvimento Empresarial pela Universidade Estácio de Sá. E-mail: alynetrindade@yahoo.com.br. $\quad$ Lattes: $\quad$ http://lattes.cnpq.br/3899209728127335. $\quad$ ORCID: https://orcid.org/0000-0002-4610-6447.

3 Doutor em Administração pela Universidade Federal do Rio de Janeiro. Professor do Mestrado em Administração e Desenvolvimento Empresarial da Universidade Estácio de Sá. Professor do Curso de Administração Pública da Universidade Federal do Estado do Rio de Janeiro. E-mail: jose.geraldo@estacio.br. Lattes: http://lattes.cnpq.br/7648617323415171. ORCID: https://orcid.org/0000-0001-6215-6084.

${ }^{4}$ Doutor em Administração pela Universidade Federal do Rio de Janeiro. Professor do Mestrado em Administração e Desenvolvimento Empresarial da Universidade Estácio de Sá. E-mail: marco.bouzada@estacio.br. Lattes: http://lattes.cnpq.br/3017782305924304. ORCID: https://orcid.org/0000-0002-7183-1325.
} 
experience (age) and (iv) analysis and reflection on the results of the evaluation of pedagogical practice, in order to improve the performance of students.

Keywords: University Management. Teacher Characteristics. ENADE. Performance.

Abstrait: Cette recherche a cherché à expliquer, à travers de multiples régressions, la relation entre 7 facteurs caractéristiques des enseignants et la performance des élèves mesurée à partir de l'examen national de performance des élèves (ENADE) et l'indicateur de la différence entre les performances observées et attendues (IDD). La recherche avec une approche quantitative a collecté des données de 63 cours / campus dans les bases de données de l'Institut national d'études et de recherche (INEP) et de l'Université Estácio de Sá (UNESA). Les résultats de la recherche indiquent la pertinence d'initiatives telles que: (i) la valorisation des professeurs titulaires d'un doctorat, (ii) l'amélioration du processus d'orientation pour la réalisation des travaux, (iii) la gestion de l'expérience pédagogique (âge) et (iv) analyse et réflexion sur les résultats de l'évaluation des pratiques pédagogiques, afin d'améliorer les performances des élèves..

Mots-clés: Gestion universitaire. Caractéristiques des enseignants. ENADE. Performance.

\section{Introdução}

As proporções gigantescas da educação superior no Brasil delineiam um setor dominado por Instituições de Ensino Superior (IES) privadas, o que torna a busca pelo desempenho uma preocupação estratégica entre os concorrentes.

A competitividade entre as IES se traduz na disputa por parcerias vantajosas com outras instituições, pelo apoio de órgãos acadêmicos, por novos investimentos e por novas matrículas (que, no caso das IES privadas, aumentarão sua receita). E a vantagem competitiva de uma IES, de acordo com a teoria da visão baseada em recursos (BARNEY, 1991; WERNERFELT, 1984), terá o docente como seu recurso mais valioso, raro e dificilmente imitável ou substituível - o que pode gerar um alto retorno por longo período e conduzir ao sucesso.

Para as IES, o sucesso é representado pelo desempenho aferido pelo Sistema Nacional de Avaliação da Educação Superior (SINAES), por meio da autoavaliação, da avaliação externa, da avaliação dos cursos de graduação, dos instrumentos de informação e do Exame Nacional de Desempenho de Estudantes (ENADE). O principal objetivo do ENADE é avaliar: o desempenho dos estudantes com relação aos conteúdos programáticos dos cursos; o desenvolvimento das competências e habilidades necessárias à formação geral e profissional; e o nível de atualização dos estudantes com relação à realidade brasileira e mundial (INEP, 2016). 
Embora seja reconhecido que outras causas também influenciam o desempenho do discente no ENADE - como por exemplo a infraestrutura escolar, as características do estudante e outros fatores desconhecidos (INEP, 2017) - a literatura referente à influência de fatores característicos do docente neste desempenho vem consolidando uma hipótese de que o desempenho docente exerce uma influência positiva significativa no desempenho discente (SILVA et al., 2016; SANTOS, 2012).

Nestas circunstâncias, este estudo tem como principal objetivo explicar a relação entre sete fatores característicos dos docentes (formação e desenvolvimento profissional, experiência no exercício do magistério, capacidade de pesquisa, remuneração, regime de trabalho, experiência em orientações e prática pedagógica) e o desempenho de seus discentes medido pelo grau obtido no ENADE. Como objetivo secundário, procurou-se verificar a relação entre os sete fatores e o grau obtido no Indicador da Diferença entre os Desempenhos Observado e Esperado (IDD). São analisados, ainda, reflexos dessa relação na gestão universitária, contribuindo para a expansão da base de conhecimento científico a respeito do tema.

\section{Fatores característicos do bom desempenho do professor universitário}

\subsection{Formação e desenvolvimento profissional}

A associação entre a titulação obtida nos programas de formação e os consequentes benefícios para os docentes, suas instituições e seus alunos, foi estudada por Zonatto et al (2013), à luz da teoria do capital humano, na qual a obtenção de novos conhecimentos e habilidades tende a aumentar o valor do capital humano em cada indivíduo. Seus achados de pesquisa, assim como outros estudos que analisaram resultados relacionados à titulação do docente (MELLO; SOUSA, 2015; MIRANDA; NOVA; CORNACCHIONE JUNIOR, 2013) confirmam que profissionais mais qualificados tendem a obter melhor desempenho. Isto sugere a pertinência do investimento em qualificação profissional do docente, por parte das instituições de ensino, na busca de um maior número de mestres e doutores.

\subsection{Experiência no exercício do magistério}

A experiência dos docentes é tratada nesta pesquisa do ponto de vista da expertise entendida como conhecimento ou habilidades em tarefas, atividades, processos ou resultados - considerando o conceito de "experience-based expert", de Collins e Evans (2002), ou seja, o expert tecnicamente qualificado (pela experiência que detém) como tomador de decisão, independentemente de qualquer diploma ou certificado. 
Os achados de pesquisa de Kini e Podolsky (2016) mostram que os docentes em geral (não apenas os universitários) melhoram seu desempenho à medida que vão se tornando mais experientes. Além das evidências da relação entre experiência e desempenho do docente, identificam-se também estudos apontando que a experiência promove uma maior habilidade na utilização de questionamentos como ferramenta do processo de construção do conhecimento e com isso há uma melhoria do desempenho discente (WANG; CHAI; HAIRON, 2016).

\subsection{Capacidade de pesquisa}

Apesar da crença de que uma maior capacidade de pesquisa tende a aumentar o desempenho do docente, existem poucas evidências empíricas que deem respaldo a esta teoria. Pan, Cotton e Murray (2014) estudaram o nexo, a complementaridade e os conflitos entre a produção científica (materialização da capacidade de pesquisa) e o ensino, sugerindo estratégias para melhor atuação. O assunto resta controverso, uma vez que também existem autores que encontraram o resultado oposto e defendem que docentes que priorizam a pesquisa tendem a desprestigiar o ensino. Bak e Kim (2015), por exemplo, avaliam o efeito dos incentivos à produção científica sobre a qualidade do ensino, concluindo que, quando estes sistemas de incentivo são empregados, é possível a atenção ser concentrada na produção científica, implicando prejuízo à qualidade do ensino.

A existência de cursos de pós-graduação stricto sensu, para Maccari et al. (2009), relacionados àqueles de graduação poderia contribuir para a capacidade de pesquisa dos professores da graduação que deles também participem.

Por outro lado, a escassez de recursos para pesquisa acaba produzindo uma competição exacerbada entre os pesquisadores dado o fato de que os "competentes" são aqueles que conseguem acessar tais recursos. O resultado dessa dinâmica em muitos casos é o estresse, cansaço e até mesmo depressão, consequências comuns ao mundo do trabalho (BOSI, 2007).

\subsection{Remuneração}

Esta pesquisa aborda a questão da remuneração como uma forma de representação do valor do professor, na medida em que professores melhores (aqueles que possuem maior titulação, mais experiência e, em geral, cujos alunos são detentores dos melhores resultados) tendem a ser mais bem remunerados (DOLTON; MARCENARO-GUITERREZ, 2011).

Dolton e Marcenaro-Gutierrez (2011) conduziram um estudo em que avaliaram o nível de remuneração de docentes (não apenas os universitários) em diferentes lugares no mundo, ratificando que a qualidade dos professores (expressa em melhores índices, como resultados em avaliações e menores taxas de reprovação e evasão de alunos, por exemplo) é 
maior nos casos em que a remuneração destes docentes se situa nos extratos mais altos da distribuição de renda dos respectivos países, pois assim a profissão atrairia os melhores quadros (quando o fator motivador for a remuneração).

\subsection{Regime de trabalho}

Sousa e Honório (2011) estudaram como a carga horária de docentes em uma IES privada se relaciona com o nível de comprometimento organizacional destes docentes, avaliando as dimensões caraterizadoras do comprometimento organizacional: afetiva; obrigação em permanecer; obrigação pelo desempenho; afiliativa; falta de recompensas e oportunidades; linha consistente de atividade; e escassez de alternativas. A pesquisa ouviu 187 docentes de ensino superior, enquadrados nas cargas horárias integral, parcial e horista, concluindo que docentes em regime integral, além de se mostrarem mais reconhecidos pelos colegas de trabalho, demonstraram um alto comprometimento nas dimensões afetiva, obrigação pelo desempenho e afiliativa.

Nesta direção, Nóvoa (1999) aponta o fenômeno conhecido como o "mal-estar docente" que se relaciona ao ambiente profissional do professor quando há deficiências em suas condições de trabalho como carga excessiva de trabalho, falta de recursos humanos e materiais, violência nas salas de aulas e esgotamento físico. Este quadro gera um desgaste biopsíquico do docente resultando em manifestações como desinteresse, apatia, desmotivação, além dos sintomas da síndrome de burnout, tais como: angústia, fobias e crises de pânico.

\subsection{Experiência em orientação}

Estudos sobre a temática da orientação, em sua maioria, tratam da postura do orientador ideal, fazendo relação, com frequência, à capacidade de pesquisa do orientador (BARRES, 2013; HARRISON, 2014; LEE, 2012). Ainda que com menos frequência, apresentam-se também estudos referentes ao processo de orientação como elemento-chave para retenção do aluno (SAMUELS, 2016).

Lee (2012) elaborou um modelo de orientação com cinco aspectos: o aspecto funcional, em que o orientador é tido como fornecedor das regras e consultor do processo; o aspecto da enculturação, onde o orientador é o representante da comunidade de pesquisa e a ponte para ingresso nessa comunidade; o aspecto do pensamento crítico, quando o orientador é responsável pelo estímulo ao aluno aos desafios da argumentação e da análise; o aspecto da emancipação, em que o orientador é um mentor para o crescimento pessoal do aluno; e o aspecto do desenvolvimento de relacionamento, cujo foco é o orientador e o aluno como uma equipe amistosa, que considera suas necessidades emocionais. Barres (2013), assim como Lee 
Revista Educação e Políticas em Debate - v. 9, n. 2, p. 489 - 508, mai./ago. 2020 - ISSN 2238-8346

(2012), reconhece a importância de se considerar o caráter emocional presente na relação orientador-orientando e o significado desta relação para o sucesso do discente e da instituição.

\subsection{Prática pedagógica}

O uso de instrumentos elaborados para a avaliação de professores por parte dos alunos, conhecidos como Student Evaluations for Teaching (SET), é atualmente uma das maneiras mais frequentes de avaliação da prática pedagógica do docente de IES (REYERO, 2014). O conteúdo dos SET varia em função das competências requeridas dos docentes, das características dos cursos e da própria instituição. Mas apesar da grande utilização do aluno como avaliador de boas práticas pedagógicas, estudos têm demonstrado que os alunos não são os mais indicados para realizar esta avaliação, pois não compreendem o que realmente os faz aprender ou, ainda, porque associam o aprendizado à dificuldade e à nota obtida nas disciplinas (PALMER, 2012).

Questão relacionada à prática pedagógica seria a receptividade da Tecnologia de Informação e Comunicação (TIC) como apoio às atividades de sala de aula.

\section{Gestão Universitária}

A relação entre o desempenho docente e o desempenho discente vem sendo estudada em diferentes pesquisas, relacionadas a um ou mais dos fatores característicos destacados no presente trabalho. Os resultados encontrados na revisão teórica e seus respectivos autores estão listados no Quadro 1. 
Revista Educação e Políticas em Debate - v. 9, n. 2, p. 489 - 508, mai./ago. 2020 - ISSN 2238-8346

QUADRO 1 - Resultados da revisão teórica sobre a relação entre o desempenho docente e o desempenho discente

\begin{tabular}{|c|c|c|}
\hline FATORES & IDEIA CENTRAL & PRINCIPAIS AUTORES \\
\hline \multirow{2}{*}{$\begin{array}{l}\text { Formação e } \\
\text { desenvolvi- } \\
\text { mento } \\
\text { profissional }\end{array}$} & $\begin{array}{l}\text { A titulação é apontada, entre as características do } \\
\text { corpo docente e da escola, não só no nível } \\
\text { universitário, como a mais forte das correlações } \\
\text { existentes com o desempenho dos alunos }\end{array}$ & Darling-Hammond (2000) \\
\hline & $\begin{array}{l}\text { Estudos que avaliaram o efeito da titulação no } \\
\text { resultado do ENADE encontraram igualmente } \\
\text { correlação positiva e a significância elevada }\end{array}$ & $\begin{array}{l}\text { Barbosa, Freire e Crisóstomo } \\
\text { (2011); Silva et al. (2016); Mello e } \\
\text { Sousa (2015); Miranda, Nova e } \\
\text { Cornacchione Junior (2013); Santos } \\
\text { (2012); Zonatto et al. (2013) }\end{array}$ \\
\hline $\begin{array}{l}\text { Regime de } \\
\text { trabalho }\end{array}$ & $\begin{array}{l}\text { Identifica-se correlação positiva entre a proporção } \\
\text { de docentes em regime integral ou dedicação } \\
\text { exclusiva e os resultados do ENADE }\end{array}$ & Silva et al. (2016); Santos (2012) \\
\hline $\begin{array}{c}\text { Prática } \\
\text { pedagógica }\end{array}$ & $\begin{array}{l}\text { Existe associação significativa entre a prática } \\
\text { pedagógica avaliada no Questionário do Estudante } \\
\text { e o desempenho dos estudantes no ENADE }\end{array}$ & Santos (2012) \\
\hline \multirow{2}{*}{$\begin{array}{l}\text { Experiência } \\
\text { em } \\
\text { orientações }\end{array}$} & $\begin{array}{l}\text { A postura do orientador explica 10,9\% da variação } \\
\text { do desempenho dos alunos }\end{array}$ & Crocker, Kahla e Allen (2014) \\
\hline & $\begin{array}{l}\text { O papel do orientador é importante para a retenção } \\
\text { do aluno }\end{array}$ & Samuels (2016) \\
\hline Remuneração & $\begin{array}{l}\text { Um aumento de } 10 \% \text { nos salários dos professores, } \\
\text { ocasiona um aumento entre } 5 \text { e } 10 \% \text { no desempenho } \\
\text { dos alunos }\end{array}$ & $\begin{array}{l}\text { Dolton e Marcenaro-Gutierrez } \\
\text { (2011) }\end{array}$ \\
\hline $\begin{array}{l}\text { Experiência } \\
\text { no exercício } \\
\text { do } \\
\text { magistério }\end{array}$ & $\begin{array}{l}\text { Relação positiva entre a experiência do professor e } \\
\text { os ganhos de desempenho de seus alunos, ao longo } \\
\text { de } 15 \text { anos }\end{array}$ & Kini e Podolsky (2016) \\
\hline $\begin{array}{l}\text { Capacidade } \\
\text { de pesquisa }\end{array}$ & $\begin{array}{l}\text { Associação positiva com os níveis de aprendizagem } \\
\text { dos alunos, evidenciando uma correlação positiva e } \\
\text { com significância. }\end{array}$ & Gralbraith e Merrill (2012) \\
\hline
\end{tabular}

Fonte: elaboração própria

De forma análoga, existem estudos que evidenciam a influência do desempenho discente sobre diversos aspectos da gestão universitária. As ideias centrais destes estudos e seus autores, selecionados na revisão teórica realizada nesta pesquisa, estão apresentados no Quadro 2. 
Revista Educação e Políticas em Debate - v. 9, n. 2, p. 489 - 508, mai./ago. 2020 - ISSN 2238-8346

QUADRO 2 - Resultados da revisão teórica sobre a relação entre o desempenho discente e outros aspectos da gestão universitária

\begin{tabular}{|c|c|c|}
\hline ASPECTOS & IDEIA CENTRAL & PRINCIPAIS AUTORES \\
\hline \multirow{4}{*}{$\begin{array}{l}\text { Uso de } \\
\text { rankings } \\
\text { acadêmicos na } \\
\text { tomada de } \\
\text { decisão }\end{array}$} & $\begin{array}{l}\text { Há uma preocupação latente com os resultados das } \\
\text { avaliações externas e os rankings elaborados a } \\
\text { partir dessas avaliações. }\end{array}$ & $\begin{array}{l}\text { Hazelkorn }(2013,2015) \text {; Jin } \\
\text { e Whalley }(2006)\end{array}$ \\
\hline & $\begin{array}{l}\text { As classificações em rankings tornaram-se uma } \\
\text { ferramenta fácil e importante para medir e comparar } \\
\text { a qualidade educacional e a excelência das IES. }\end{array}$ & Hazelkorn (2013) \\
\hline & $\begin{array}{l}\text { As classificações estão sendo empregadas (tanto em } \\
\text { IES públicas quanto privadas) no apoio às tomadas de } \\
\text { decisões estratégicas sobre parcerias, financiamento, } \\
\text { patrocínio e recrutamento de colaboradores. }\end{array}$ & Hazelkorn $(2013,2015)$ \\
\hline & $\begin{array}{l}\text { Alunos usam os rankings para escolherem a IES } \\
\text { onde estudarão, pois os associam à posição } \\
\text { institucional e à sua reputação. }\end{array}$ & $\begin{array}{l}\text { Ehrenberg (2004); } \\
\text { Hazelkorn (2013) }\end{array}$ \\
\hline $\begin{array}{l}\text { Monitoramento } \\
\text { de indicadores } \\
\text { por gestores }\end{array}$ & $\begin{array}{l}\text { Um mapeamento dos indicadores de avaliação da } \\
\text { gestão universitária na literatura nacional e } \\
\text { internacional, de } 1987 \text { a } 2015 \text {, encontrou cerca de } \\
350 \text { indicadores: } 80 \% \text { na literatura internacional, } \\
\text { nas dimensões Ensino, Pesquisa, Extensão e } \\
\text { Gestão; } 83 \% \text { mediam aspectos não financeiros; } 42 \% \\
\text { estavam na dimensão Gestão, onde predominam } \\
\text { aspectos financeiros; 33\% estavam na dimensão } \\
\text { Ensino (aspectos não financeiros); havia carência } \\
\text { de indicadores de monitoramento das estratégias e } \\
\text { do alcance dos resultados organizacionais. }\end{array}$ & Nuernberg et al. (2016) \\
\hline $\begin{array}{l}\text { Desempenho } \\
\text { Econômico e } \\
\text { financeiro }\end{array}$ & $\begin{array}{l}\text { IES com melhor avaliação acadêmica no Provão } \\
\text { (atualmente substituído pelo ENADE) obtiveram } \\
\text { retornos financeiros (Retorno Sobre o Ativo e pelo } \\
\text { Retorno Sobre a Receita) maiores do que as mal } \\
\text { avaliadas, demonstrando correlação positiva e } \\
\text { estatisticamente significante, em um modelo que } \\
\text { explicava } 71 \% \text { dos dados. }\end{array}$ & Rocha e Machado (2003) \\
\hline
\end{tabular}

Fonte: elaboração própria

\section{Metodologia}

A pesquisa em questão tem uma abordagem quantitativa e pode ser classificada, quanto aos fins, como explicativa - seu objetivo é esclarecer a influência dos fatores característicos do desempenho do docente (variáveis explicativas) sobre o desempenho do discente (variável dependente) - e, quanto aos meios, como documental, pois a pesquisa documental é aquela realizada em documentos guardados por órgãos públicos e privados de qualquer natureza ou com pessoas: registros, anais, ofícios, etc (VERGARA, 2014).

A população deste estudo é definida pelos cursos de graduação em ciências sociais e negócios, com diploma de bacharel, pertencentes à grande área "ciências sociais, negócios e direito”, participantes do ENADE 2015, oferecidos na modalidade presencial no Brasil, ou 
seja, os bacharelados em Administração, Ciências Contábeis, Ciências Econômicas, Jornalismo, Publicidade e Propaganda, Psicologia, Relações Internacionais, Secretariado Executivo, Administração Pública e Teologia.

Embora os cursos de Direito, Design e Turismo também sejam cursos de bacharelado avaliados no ENADE 2015, estes não foram considerados na população por diferentes motivos. O curso de Direito possui se distingue dos demais cursos da grande área "ciências sociais, negócios e direito", a ponto de ser citada individualmente no nome da área, não se caracterizando como pertencente às ciências sociais ou negócios. Os cursos de Design e de Turismo não são da grande área "ciências sociais", foco desta pesquisa (o curso de Design é pertencente à grande área "humanidades e artes" e o curso de Turismo, por sua vez, pertence à grande área "serviços").

A amostra - selecionada intencionalmente, por se tratar de IES do segundo maior grupo privado existente na educação superior no Brasil e, ainda, pela conveniência do fácil acesso aos dados - engloba estes cursos, cujos concluintes foram avaliados no ENADE 2015, em todas as unidades fluminenses da Universidade Estácio de Sá (UNESA) que oferecem estes cursos (exceto os cursos de Administração Pública e Teologia, por não serem oferecidos pela UNESA). Estas unidades estão localizadas em 15 municípios do estado do Rio de Janeiro (RJ), a saber, Angra dos Reis, Cabo Frio, Campos dos Goytacazes, Duque de Caxias, Macaé, Niterói, Nova Friburgo, Nova Iguaçu, Petrópolis, Queimados, Resende, Rio de Janeiro, São Gonçalo, São João de Meriti e Teresópolis, perfazendo um total de 63 cursos/campi.

O Quadro 3 apresenta os fatores característicos do desempenho docente e as respectivas variáveis coletadas para todos os cursos da amostra, no horizonte temporal de 2011 a 2015, no intuito de englobar cursos com a duração de até 5 anos. 
QUADRO 3 - Fatores característicos do docente

\begin{tabular}{|c|c|c|}
\hline Fator & Natureza do dado coletado & $\begin{array}{l}\text { Fonte do } \\
\text { dado }\end{array}$ \\
\hline \multirow{2}{*}{$\begin{array}{l}\text { Formação e } \\
\text { desenvolvimento } \\
\text { profissional }\end{array}$} & $\begin{array}{l}\text { Componente do Conceito Preliminar de Curso (CPC)_2015 } \\
\text { "Nota padronizada de Proporção de Mestres" }\end{array}$ & \multirow{4}{*}{$\begin{array}{c}\text { Instituto } \\
\text { Nacional } \\
\text { de } \\
\text { Estudos e } \\
\text { Pesquisas } \\
\text { (INEP) }\end{array}$} \\
\hline & $\begin{array}{l}\text { Componente do CPC_2015 "Nota padronizada de } \\
\text { Proporção de Doutores" }\end{array}$ & \\
\hline Regime de trabalho & $\begin{array}{l}\text { Componente do CPC_2015 "Nota padronizada de Regime } \\
\text { de Trabalho" }\end{array}$ & \\
\hline Prática pedagógica & $\begin{array}{l}\text { Componente do CPC_2015 "Nota padronizada da } \\
\text { Organização Didático-Pedagógica” }\end{array}$ & \\
\hline $\begin{array}{l}\text { Experiência no exercício } \\
\text { do magistério }\end{array}$ & Idade dos professores no final de 2015 & \multirow{4}{*}{ UNESA } \\
\hline Capacidade de pesquisa & $\begin{array}{l}\text { Quantidade de produções bibliográficas dos professores no } \\
\text { período de } 2011 \text { a } 2015\end{array}$ & \\
\hline Remuneração & $\begin{array}{l}\text { Valor da hora aula médio dos professores no período de } \\
2011 \text { a } 2015\end{array}$ & \\
\hline $\begin{array}{l}\text { Experiência em } \\
\text { Orientações }\end{array}$ & $\begin{array}{l}\text { Quantidade de Orientações concluídas pelos professores no } \\
\text { período de } 2011 \text { a } 2015\end{array}$ & \\
\hline
\end{tabular}

Fonte: elaboração própria

O Quadro 4 apresenta os indicadores do desempenho discente e a respectiva variável coletada para todos os cursos da amostra.

QUADRO 4 - Indicadores do desempenho discente

\begin{tabular}{|l|l|c|}
\hline $\begin{array}{c}\text { Indicadores de } \\
\text { desempenho } \\
\text { discente }\end{array}$ & \multicolumn{1}{|c|}{ Variável dependente } & Fonte do dado \\
\hline ENADE & Nota bruta geral do curso no ENADE & INEP \\
\hline IDD & Componente do CPC_2015 “Nota padronizada do IDD” & INEP \\
\hline
\end{tabular}

Fonte: elaboração própria

As variáveis dos Quadros 3 e 4 permitiram atender aos objetivos desta pesquisa "explicar, por meio de regressões múltiplas, a relação entre 7 fatores característicos dos docentes e o desempenho dos discentes medido a partir do ENADE e IDD”.

Para os dados oriundos da UNESA, mediante contato autorizado com a Divisão de Pesquisa da Vice-presidência de Ensino da UNESA, foi obtida uma planilha Excel contendo os dados disponíveis dos docentes (idade dos professores no final de 2015, quantidade de produções bibliográficas dos professores no período de 2011 a 2015, Valor da hora aula dos 
professores no período de 2011 a 2015 e quantidade de orientações concluídas pelos professores no período de 2011 a 2015).

Os dados foram tratados calculando-se, para cada curso/campus, as médias ponderadas da produção bibliográfica docente, das orientações concluídas por docente, dos valores das horas aula e das idades dos professores. O peso usado para a ponderação foi a média da carga horária total do professor, naquele curso/campus, no período de 2011 a 2015. A partir deste tratamento, foram geradas as variáveis explicativas representativas dos quatro últimos fatores do Quadro 3: fatores capacidade de pesquisa, experiência em orientações, remuneração e experiência no exercício do magistério, respectivamente.

Para os três primeiros fatores deste quadro, foram necessários dados oriundos do INEP. Foi consultado, então, o resultado do Conceito Preliminar de Curso disponível no próprio sítio do Instituto e foi elaborada uma planilha com os dados de interesse desta pesquisa: Nota padronizada de Proporção de Mestres, Nota padronizada de Proporção de Doutores, Nota padronizada de Regime de Trabalho, Nota padronizada da Organização DidáticoPedagógica, Nota bruta geral do curso no ENADE e Nota padronizada do IDD. Estes dados não necessitaram de tratamento, pois já estavam calculados.

Com estes dados, foi criada uma planilha onde estão dispostas as oito variáveis explicativas, a variável dependente Nota bruta do curso no ENADE (necessária para testar as primeiras oito hipóteses) e a variável dependente Nota padronizada do IDD (necessária para o teste das hipóteses 9 a 16). Um extrato destes dados pode ser visualizado na Tabela 1, a seguir. 
TABELA 1 - Variáveis explicativas e variáveis dependentes

\begin{tabular}{|c|c|c|c|c|c|c|c|c|c|c|}
\hline Curso-campus & $\begin{array}{c}\text { Nota } \\
\text { pdz } \\
\text { Orgz } \\
\text { Did- } \\
\text { Ped }\end{array}$ & $\begin{array}{l}\text { Nota } \\
\text { pdz } \\
\text { Mestr }\end{array}$ & $\begin{array}{l}\text { Nota } \\
\text { pdz } \\
\text { Dout }\end{array}$ & $\begin{array}{l}\text { Nota } \\
\text { pdz } \\
\text { Reg } \\
\text { Trab }\end{array}$ & $\begin{array}{l}\text { Capa- } \\
\text { cidade } \\
\text { Pesq }\end{array}$ & $\begin{array}{l}\text { Orien- } \\
\text { tações }\end{array}$ & $\begin{array}{c}\text { Exp. } \\
\text { Magis- } \\
\text { tério } \\
\text { (idade) }\end{array}$ & $\begin{array}{l}\text { Remu- } \\
\text { neração }\end{array}$ & $\begin{array}{c}\text { Nota } \\
\text { Bruta } \\
\text { ENA } \\
\text { DE }\end{array}$ & $\begin{array}{l}\text { Nota } \\
\text { pdrz } \\
\text { IDD }\end{array}$ \\
\hline $\begin{array}{l}\text { ADMINISTRAÇÃO- } \\
\text { BARRA I - } \\
\text { TOM JOBIM }\end{array}$ & 3,03 & 4,77 & 4,58 & 4,18 & 1,78 & 0,72 & 56,56 & 48,23 & 46,60 & 3,37 \\
\hline $\begin{array}{l}\text { ADMINISTRAÇÃO- } \\
\text { CABO FRIO }\end{array}$ & 3,48 & 4,65 & 4,40 & 4,29 & 1,69 & 3,27 & 47,50 & 36,37 & 46,28 & 3,42 \\
\hline $\begin{array}{l}\text { ADMINISTRAÇÃO- } \\
\text { DUQUE DE CAXIAS }\end{array}$ & 3,14 & 4,58 & 4,33 & 3,46 & 0,70 & 0,24 & 47,65 & 44,61 & 41,44 & 2,70 \\
\hline$(\ldots)$ & & & & & & & & & & \\
\hline $\begin{array}{l}\text { RELAÇÕES } \\
\text { INTERNACIONAIS- } \\
\text { NOVA AMÉRICA }\end{array}$ & 2,73 & 4,31 & 3,75 & 3,78 & 2,72 & 2,08 & 52,79 & 45,61 & 39,20 & 1,10 \\
\hline $\begin{array}{l}\text { SECRETARIADO } \\
\text { EXECUTIVO } \\
\text { TRILINGÜE- } \\
\text { CENTRO I - } \\
\text { PRESIDENTE } \\
\text { VARGAS }\end{array}$ & 0,00 & 4,83 & 5,00 & 4,43 & 1,01 & 1,02 & 50,87 & 49,29 & 50,27 & 1,59 \\
\hline
\end{tabular}

Fonte: dados da pesquisa

Pressupondo-se que as características do corpo docente exercem influência significativamente positiva sobre o desempenho discente, foram definidas as hipóteses de pesquisa $\mathrm{H} 1 \mathrm{a} \mathrm{H} 8$, referentes ao objetivo principal desta pesquisa, conforme a figura 1.

Figura 1 - Hipóteses referentes ao objetivo principal

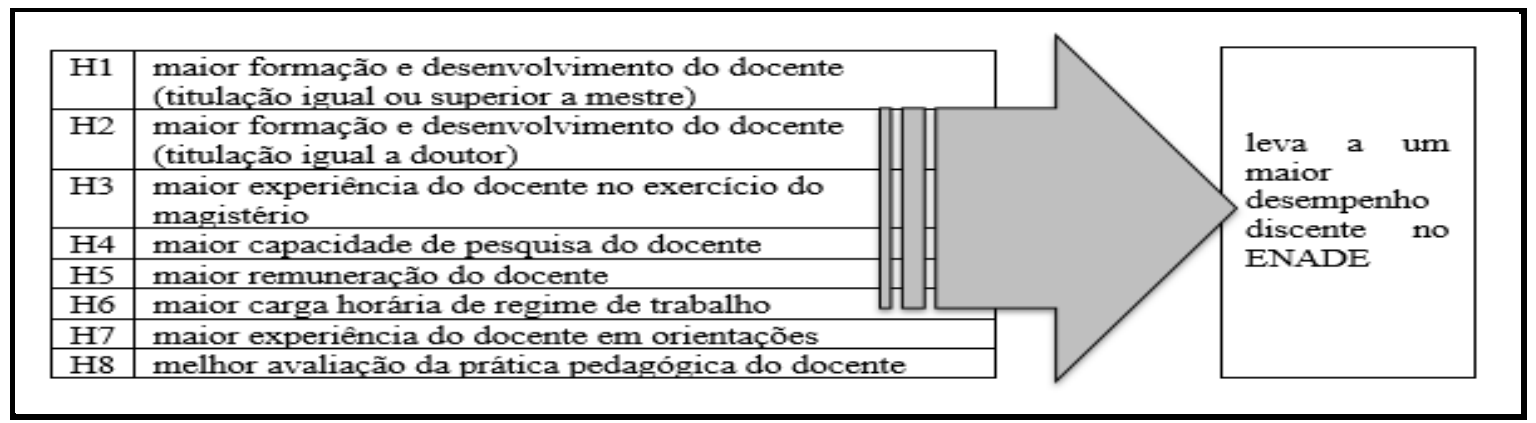

Fonte: Elaboração própria 
Pressupondo-se que as características do corpo docente exerçam influência sobre o desempenho do discente, considerando o valor agregado à sua educação durante o curso, foram definidas as hipóteses de pesquisa H9 a H16, conforme a figura 2.

Figura 2 - Hipóteses referentes ao objetivo secundário

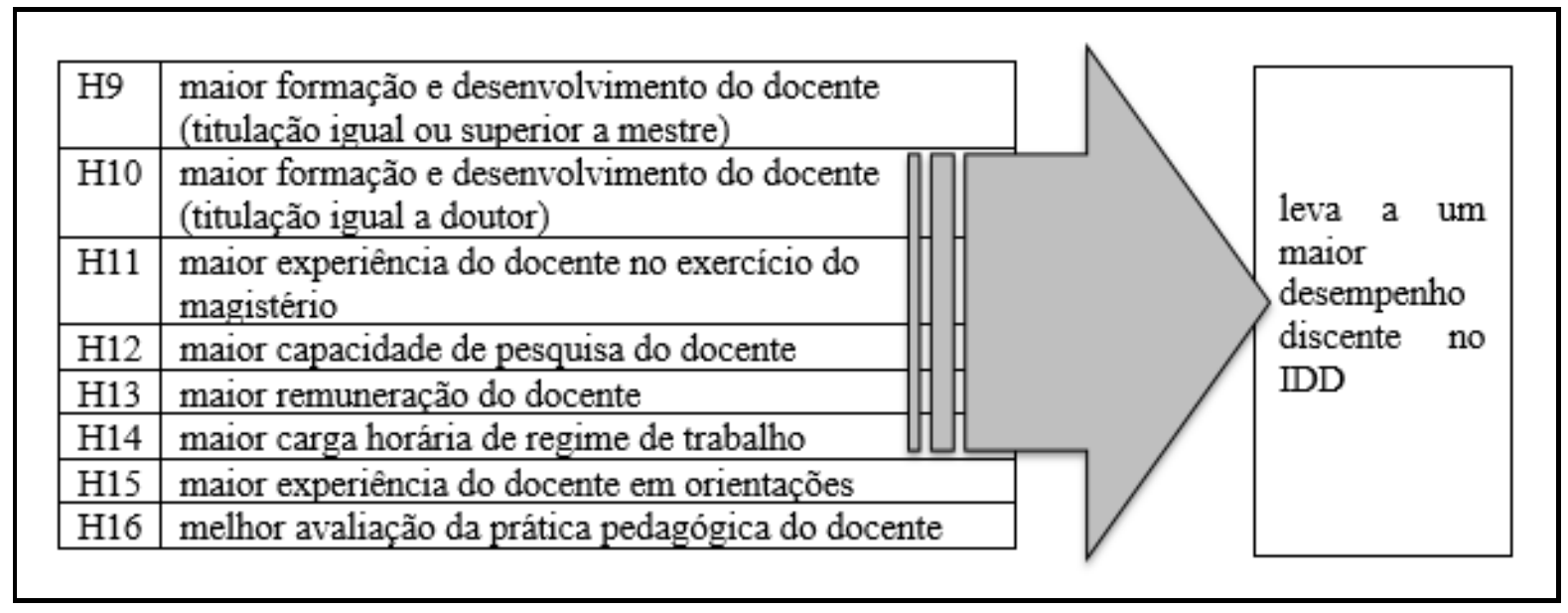

Fonte: Elaboração própria

Visando atender ao objetivo principal desta pesquisa - explicar a relação entre os 7 fatores característicos do desempenho dos docentes e o desempenho discente - e testar as 8 primeiras hipóteses de pesquisa, foi rodada uma regressão múltipla, para os 63 cursos/campi dos 15 municípios, tendo como variáreis explicativas as 8 referentes aos 7 fatores característicos do desempenho docente (Quadro 3) e, como variável dependente, a nota do curso no ENADE (Quadro 4), com base nos valores expostos na Tabela 1.

Para atender ao objetivo secundário desta pesquisa - explicar a relação entre os fatores característicos dos docentes e o desempenho discente no IDD - e testar as hipóteses de pesquisa de número 9 a 16, foi rodada a mesma regressão múltipla referente ao objetivo principal, desta vez utilizando como variável dependente, ao invés da nota do ENADE, a nota padronizada do IDD do curso.

\section{Apresentação e análise dos resultados}

Por questão de espaço, os resultados das regressões múltiplas não foram inseridos no artigo, mas estão disponíveis para consultas futuras. 


\subsection{Análise dos coeficientes angulares das variáveis e Identificação dos valores-P relevantes no ENADE}

O resultado do teste das hipóteses $\mathrm{H}_{1}$ a $\mathrm{H} 8$, relativas ao objetivo principal desta pesquisa - explicar a relação entre os 7 fatores característicos dos docentes e o desempenho discente - mostra que nenhuma das hipóteses foi confirmada.

No que diz respeito à análise dos valores-P, apenas as variáveis Orientações e Experiência no magistério (idade) apresentaram valores relevantes, a 10\% de significância, mas a influência identificada foi negativa (e não positiva, como previam as hipóteses de pesquisa).

No tocante ao fator experiência em orientações, a correlação com o desempenho discente apresenta significância, da mesma forma que demonstraram os estudos de Crocker, Kahla e Allen (2014), embora os mesmos tenham identificado uma influência positiva. A diferença do sinal do coeficiente angular pode ter explicação, primeiro, na própria limitação da variável usada nesta pesquisa, que considera apenas o número de orientações realizadas pelo docente (enquanto Crocker, Kahla e Allen mediram o conjunto de medidas consideradas eficazes em orientação) ou, segundo, em um impacto negativo causado por uma possível sobrecarga do número de orientandos do docente (quanto mais orientandos, mais sobrecarregado e menos eficiente o professor, ou seja, uma grande quantidade de orientações pode atrapalhar as aulas).

No que diz respeito ao fator experiência no exercício do magistério (idade), foi identificada uma correlação significativa entre este fator e o desempenho discente, tal e qual identificaram Kini e Podolsky (2016), embora essas autoras tenham encontrado uma influência positiva e, na presente pesquisa, tenha sido encontrada uma influência negativa. Ressalte-se, no entanto, que a variável escolhida para representar este fator (variável idade) carrega duas limitações importantes: primeiro, o risco de a idade não corresponder proporcionalmente aos anos de exercício do magistério; e segundo, o fato de a variável não considerar a experiência profissional fora do magistério associada à disciplina que o docente ministra - por exemplo, os anos de serviço do contador experiente (em empresas) que ministra disciplinas de ciências contábeis. Por outro lado, este resultado pode estar apontando o distanciamento e a falta de conexão entre os professores mais velhos e os alunos de graduação, o que seria minimizado com o emprego de professores mais jovens, de uma geração que partilhe dos mesmos hábitos e costumes dos jovens alunos.

Em linhas gerais, os resultados desta regressão refutam os resultados encontrados pelos autores que estudaram a influência dos fatores titulação (BARBOSA; FREIRE; CRISÓSTOMO, 2011; SILVA et al., 2016; MELlO; SOUSA, 2015; MIRANDA; NOVA; CORNACCHIONE JUNIOR, 2013; SANTOS, 2012; ZONATTO et al., 2013) e regime de trabalho (SLVA et al., 2016; SANTOS, 2012) no ENADE e encontraram influência positiva e significância elevada. Não obstante a existência do risco de que a amostra da presente pesquisa, 
concentrada na UNESA, não represente o universo dos cursos avaliados no Brasil, registrando assim resultados tão diferentes, não se pode deixar de mencionar que, até o exame de 2014, o INEP considerava como ponto de observação o curso/instituição/município e, no exame de 2015, cujos resultados foram divulgados com atraso no primeiro semestre de 2017, pela primeira vez foi usado como ponto de observação o curso/instituição/campus, empregando assim uma observação mais criteriosa, capaz de registrar as diferenças entre os campus, que anteriormente eram agrupados, mesmo sendo sabido que as diferentes características dos alunos de diferentes localidades interferem no seu desempenho escolar.

\subsection{Análise dos coeficientes angulares das variáveis e Identificação dos valores-P relevantes no IDD}

O resultado do teste das hipóteses H9 a H16, relativas ao primeiro objetivo secundário - explicar a relação entre os fatores característicos dos e o desempenho discente no IDD mostra que apenas as hipóteses H10 (maior formação e desenvolvimento do docente, titulação igual a doutor, leva a um melhor desempenho discente no IDD) e H16 (melhor avaliação da prática pedagógica do docente leva a um melhor desempenho discente no IDD) foram confirmadas. As demais hipóteses foram rejeitadas.

No tocante à análise dos valores-P, apenas as variáveis Nota Padronizada de Doutores, Nota Padronizada de Organização Didático-pedagógica e Orientações apresentaram valores relevantes, a $10 \%$ de significância. No que diz respeito à análise dos coeficientes angulares, percebe-se que as Notas Padronizadas de Organização Didático-pedagógica e de Doutores exercem uma influência positiva, mas Orientações exerce uma influência negativa.

A influência positiva significativa do fator titulação (titulação igual a doutor) corrobora os achados de Darling-Hammond (2000) e os resultados encontrados por Zonatto et al. (2013) sobre a influência positiva dos docentes com nível stricto sensu nos resultados do ENADE 2009. Os autores que analisaram o impacto no ENADE haviam encontrado a mesma relação positiva e significativa, mas note-se que, em seus estudos, empregaram a variável Nota Padronizada de Mestres (titulação igual ou superior a mestre).

A relevância da influência positiva do fator prática pedagógica confronta os resultados de Silva et al (2016), que não encontraram significância na correlação, mas ratifica os achados de Santos (SANTOS, 2012).

A correlação entre o fator experiência em orientações e o desempenho discente no IDD mostrou a mesma influência negativa significativa do primeiro no segundo, anteriormente encontrada no ENADE. 


\section{Conclusão}

Com uma abordagem quantitativa e empregando regressões múltiplas, esta pesquisa teve como objetivo principal explicar a relação entre os fatores característicos do docente e o desempenho discente aferido pelo resultado no ENADE. Como objetivo secundário, procurou explicar a mesma relação com o desempenho no IDD.

Os achados desta pesquisa mostraram que somente os fatores "experiência no exercício do magistério" e "experiência em orientações" influenciaram significativamente o desempenho no ENADE, embora tenha sido uma influência negativa. Quanto à influência no IDD, os fatores "formação e desenvolvimento profissional" e "prática pedagógica" apresentaram influência positiva significativa. O fator "experiência em orientações" também apresentou influência significativa negativa como no caso do ENADE (Tabela 4).

Foram encontrados, nesta pesquisa, resultados destoantes daqueles comumente encontrados na literatura e a maioria das hipóteses de pesquisa foi rejeitada. Isso pode ter ocorrido por inúmeros motivos, dentre os quais destacam-se três: primeiro, a amostra foi selecionada intencionalmente, por se tratar do segundo maior grupo privado da educação superior nacional e, ainda, pela conveniência do acesso facilitado aos dados, estando todos os cursos/campi concentrados no estado do Rio de Janeiro, o que gera o risco de a amostra não representar o universo, ocasionando uma limitação do método; segundo, o Conceito ENADE e o Conceito Preliminar de Curso (usados pelos autores que compõem o referencial teórico) que até então eram calculados por município, pela primeira vez foram realizados por curso/campus, tornando os resultados mais fidedignos que os anteriores, onde se misturavam campi heterogêneos e as modalidades de ensino presencial e a distância (INEP, 2017); e terceiro, não foram identificados outros estudos cuja metodologia tenha previsto a ponderação da participação do docente no curso em função de sua carga horária no curso, como foi feito na presente pesquisa, o que torna o presente estudo, neste quesito, mais minucioso do ponto de vista da análise estatística de algumas das variáveis.

A principal contribuição teórica desta pesquisa refere-se às poucas corroborações e muitas divergências em relação à literatura, em um momento de mudança no formato de apresentação dos dados pelo INEP. Uma outra contribuição ao avanço da teoria é a maneira pouco comum com que o assunto foi tratado, tentando estabelecer um elo interdisciplinar entre os estudiosos da gestão e os da educação, incentivando o diálogo entre as duas partes. Os parágrafos a seguir apresentam as implicações práticas da pesquisa.

A partir dos resultados do presente estudo, recomenda-se que sejam exploradas estruturas de avaliação de scorecards de Recursos Humanos (RH) com indicadores baseados nas 
características de desempenho dos docentes analisadas, especialmente aquelas que mostraram maior significância - influência negativa da experiência no exercício do magistério (no modelo com o ENADE), influência positiva da prática pedagógica e formação e desenvolvimento profissional (no modelo com o IDD) e influência negativa da experiência em orientações (em ambos os modelos) - permitindo, assim, explicitar a ligação entre o docente e a geração de valor e, ainda, gerenciar o docente como o recurso mais valioso.

No nível gerencial, recomenda-se: a) investigar os motivos pelos quais o esperado ganho de desempenho de alunos de professores com maior experiência no magistério (idade) não está se concretizando, neutralizando esses motivos; b) valorizar o processo de avaliação da prática pedagógica, seja habilitando os alunos para bem realizá-la, seja instituindo a avaliação do docente realizada por pares; c) valorizar os professores doutores, mediante uma política de compensação financeira e/ou oferta de oportunidades de desenvolvimento profissional, e investigar o motivo da contribuição menos significativa dos mestres, priorizando no processo de contratação a titulação em área associada à disciplina e a qualidade da instituição de origem do docente; e d) investigar o processo de orientação, de forma a diagnosticar suas falhas e adotar melhores práticas para alavancar o sucesso do aluno.

Um outro ponto de inquietação suscitado pelos resultados desta pesquisa é a aparente dicotomia entre dois diferentes pontos de vista sobre a avaliação: o da gestão e o pedagógico. Isso é demonstrado pela diferença existente entre os resultados alcançados nos modelos do ENADE (cujo resultado tem impacto financeiro e na tomada de decisão do gestor) e do IDD (que ressalta o verdadeiro valor agregado ao discente), mostrando que, o que é bom para a gestão e para o desempenho financeiro da IES (ROCHA; MACHADO, 2003), nem sempre é o melhor em termos de ganho de aprendizado para o aluno. Construir scorecards de RH, considerando o docente como o recurso mais valioso do ponto de vista da Resource Based View Theory $(R B V T)$, tentando reduzir a citada dicotomia, é um desafio que ora se apresenta.

Para novas pesquisas, como sugestão, recomenda-se que sejam realizados estudos que para conceber um novo modelo, capaz de melhor explicar quantitativamente a relação entre as características do docente e o desempenho discente, permitindo novos ganhos nos campos da educação e da gestão universitária - eventualmente, com outros métodos e outras amostras, com heterogeneidade geográfica e institucional. Sugere-se, ainda, que nesses estudos sejam tratadas as limitações das variáveis empregadas na presente pesquisa. Em uma abordagem qualitativa, para melhor compreensão das relações que não confirmaram a teoria pré-existente, sugere-se o emprego de entrevistas semi-estruturadas que possibilitem uma análise acerca da percepção sobre os motivos envolvidos - questione-se, por exemplo: por que professores com 
maior carga horária não estão levando a um melhor desempenho do aluno? O que pensam a este respeito alunos, professores (com alta e baixa carga horária) e coordenadores de curso?

Pelos motivos expostos, este estudo pode vir a ser de interesse de todas as IES (públicas ou privadas), devido à importância dos resultados do ENADE para valorização dos cursos e, ainda, para obtenção dos repasses de recursos do governo, no caso das instituições públicas. Poderá também contribuir para a melhoria da gestão do desempenho das IES, ao identificar quais fatores característicos do desempenho do docente devem ser o foco da ação gerencial e pedagógica e, assim, gerar subsídios para apoiar a tomada de decisão, sempre visando à melhoria da qualidade dos cursos, o que certamente impacta a geração de receita.

\section{Referências}

BAK, H. J.; KIM, D. H. Too much emphasis on research? An empirical examination of the relationship between research and teaching in multitasking environments. Research in Higher Education Policy Analysis Archives, v. 56, n. 8, p. 843-860, 2015. DOI: https://doi.org/10.1007/s11162-015-9372-0.

BARBOSA, G. D. C.; FREIRE, F. D. S.; CRISÓSTOMO, V. L. Análise dos indicadores de desempenho de gestão das IFES e o desempenho discente no ENADE. Avaliação: Revista da Avaliação da Educação Superior (Campinas), v. 16, n. 2, p. 317-344, 2011. DOI: https://doi.org/10.1590/s 1414-40772011000200005.

BARNEY, J. B. Firm resources and sustained competitive advantage. Journal of

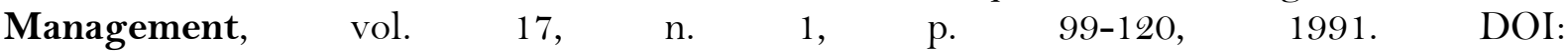
https://doi.org/10.1177/014920639101700108.

BARRES, B. A. How to pick a graduate advisor. Neuron, v. 80, n. 2, p. 275-279, 2013. DOI: https://doi.org/10.1016/j.neuron.2013.10.005.

BOSI, A. P. A precarização do trabalho docente nas instituições de ensino superior do Brasil nesses últimos 25 anos. Educação \& Sociedade, Campinas, v. 28, n. 101, p. 1503-1523, set./dez. 2007. DOI: https://doi.org/10.1590/s0101-73302007000400012.

COLLINS, H. M.; EVANS, R. The third wave of science studies: studies of expertise and experience. Social Studies of Science, v. 32, n. 2, p. 235-296, 2002. DOI: https://doi.org/10.1177/0306312702032002003.

CROCKER, R. M.; KAHLA, M.; ALLEN, C. Fixing advising : a model for faculty advising. Research in Higher Education, v. 26, p. 1-9, 2014.

DARLING-HAMMOND, L. Teacher quality and student achievement: a review of state policy evidence previous research. Education Policy Analysis Archives, v. 8, n. 1, p. 1-44, 2000. DOI: https://doi.org/10.14507/epaa.v8n1.2000. 
DOLTON, P.; MARCENARO-GUITERREZ, O. D. Teacher pay and pupil performance. Economic Policy, n. 1, p. 5-55, 2011. DOI: https://doi.org/10.1111/j.1468-0327.2010.00257.x.

EHRENBERG, R. G. Econometric Studies of Higher Education. Journal of Econometrics, v. 121, n. $1-2$, p. $19-37,2004$.

GALBRAITH, C. S.; MERRILL, G. B. Faculty research productivity and standardized student learning outcomes in a university teaching environment: a bayesian analysis of relationships. Studies in Higher Education, v. 37, n. 4, p. 469-480, 2012. DOI: https://doi.org/10.1080/03075079.2010.523782.

HARRISON, E. M. The Faculty Advisor Evaluation Questionnaire: psychometric properties. Nursing Education Perspectives, v. 35, n. 6, p. 380-386, 2014. DOI: https://doi.org/10.5480/12-916.1.

HAZELKORN, E. How Rankings are Reshaping Higher Education. In: Los Rankings Univeritarios. Mitos y Realidades. Madrid, 2013.

HAZELKORN, E. Rankings and the reshaping of higher education: the battle for world class excellence. 2. ed. Basingstoke: Palgrave Macmillan, 2015.

INEP. Nota Técnica Nr 03/2017/CGCQES/DAES. Brasília: INEP, 2017.

JIN, G. Z.; WHALLEY, A. US News Rankings and college reactions. 2006. 48 p.

KINI, T.; PODOLSKY, A. Does teaching experience increase teacher effectiveness? A review of the research. Palo Alto: Learning Policy Institute, 2016. 72 p. (Report)

LEE, A. Successful research supervision: advising students doing research. New York: Routldge, 2012.200 p.

MACCARI, E. A.; LIMA, M.C.; RICCIO, E.L. Uso do Sistema de Avaliação da Capes por Programas de Pós-Graduação em Administração no Brasil. Revista de Ciências da Administração, [S.L], $\quad$ v. 2 , $\quad$ n. $25, \quad$ p. $68-96$, set./dez. 2009. DOI: https://doi.org/10.5007/2175-8077.2009v11n25p68.

MELLO, J.; SOUSA, F. Caminhos formacionais na engenharia de produção: a formação docente e os resultados do ENADE 2011. Revista Gestão Universitária na América Latina-GUAL, v. 8, n. 2, p. 199-215, 2015. DOI: https://doi.org/10.5007/1983-4535.2015v8n2p199.

MIRANDA, G. J.; NOVA, S. P. DE C. C.; CORNACCHIONE JUNIOR, E. B. To sir with love: the relations between teacher qualification and student performance in Accounting. Business Management Review, v. 15, n. 48, p. 462-480, 2013. DOI: https://doi.org/10.7819/rbgn.v15i48.1351.

NÓVOA, A. Os Professores na Virada do Milênio: do excesso dos discursos à pobreza das práticas. Educação e Pesquisa, São Paulo, v. 25, n. 1, p. 11-20, jan./jun. 1999. DOI: https://doi.org/10.1590/s1517-97021999000100002. 
NUERNBERG, E.; ENSSLIN, S. CARDOSO, T.; VALMORBIDA, S. Gestão universitária: identificação e análise dos indicadores utilizados na literatura. CONTEXTUS Revista Contemporânea de Economia e Gestão, v. 14, n. 3, p. 14-3, 2016. DOI: https://doi.org/10.19094//contextus.v14i3.822.

PALMER, S. Student evaluation of teaching: keeping in touch with reality. Quality in higher $\begin{array}{lllllll}\text { education, } & \text { v. } 18, & \text { n. } 3, & \text { p. } & 297-311, & 2012 . & \text { DOI: }\end{array}$ https://doi.org/10.1080/13538322.2012.730336.

PAN, W.; COTTON, D.; MURRAY, P. Linking research and teaching: context, conflict and complementarity. Innovations in Education \& Teaching International, v. 51, n. 1, p. 3-14, 2014. DOI: https://doi.org/10.1080/14703297.2013.847794.

REYERO, D. Teaching excellence at the university. Analysis and proposals for better evaluation of university teacher. Educación XX1, v. 17, n. 2, p. 125-143, 2014.

ROCHA, C. H.; MACHADO, A. L. M. O desempenho universitário acadêmico-pedagógico versus o desempenho financeiro. Revista de Economia Contemporânea, v. 7, n. 1, p. 161 $168,2003$.

SAMUELS, H. B. Comprehensive academic undergraduate advising services: one university's successful model. 2016. 189 p. Thesis (Doctor of Education in Educational Leadership Studies) - West Virginia University, Morgantown. DOI: https://doi.org/10.33915/etd.6562.

SANTOS, N. DE A. Determinantes do desempenho acadêmico dos alunos do curso de ciências contábeis. 2012. 257 p. Tese (Doutorado em Controladoria e Contabilidade) Universidade de São Paulo, São Paulo. DOI: https://doi.org/10.11606/t.12.2012.tde$11062012-164530$.

SILVA, F.; PROTAZIO, B.; SILVA, L.; CASTRO, M. . Influência dos fatores organizacionais e ambientais no desempenho dos estudantes no ENADE. XIX SEMEAD Seminários em Administração. Anais... São Paulo: 2016.

SOUSA, J. S.; HONÓRIO, L. C. Comprometimento organizacional: avaliando professores universitários em regimes diferenciados de carga horária de trabalho. XXXV Encontro da ANPAD. Anais... Rio de Janeiro: 2011.

VERGARA, S. C. Projetos e Relatórios de Pesquisa em Administração. 15. ed. São Paulo: Atlas, 2014. 94 p.

WANG, A.; CHAI, C. S.; HAIRON, S. Exploring the impact of teacher experience on questioning techniques in a Knowledge Building classroom. Computers in Education Journal, April, 2016. DOI: https://doi.org/10.1007/s40692-016-0057-2.

WERNERFELT, B. A Resource-based View of the Firm. Strategic Management Journal, v. 5, n 2, p. 171-180, 1984.

ZONATTO, V.; DALlabONA, L.; MOURA, G.; DOMINGUES, M.; RAUSCH, R.. Evidências da Relação entre Qualificação Docente e Desempenho Acadêmico: uma análise à luz da Teoria do Capital Humano. Sociedade, Contabilidade e Gestão, v. 8, n. 1, p. 6-25, jan. 2013. DOI: https://doi.org/10.21446/scg_ufrj.v8i1.13280. 